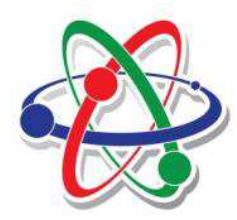

Open Medscience

Peer-Reviewed Open Access

JOURNAL OF DIAGNOSTIC IMAGING IN THERAPY

Journal homepage: www.openmedscience.com

Review Article

\title{
Basic Premises to Molecular Imaging and Radionuclide Therapy - Part 1
}

\author{
Luigi Mansi ${ }^{1, *}$, Sean L Kitson ${ }^{2}$, Vincenzo Cuccurullo ${ }^{1}$, Andrea Ciarmiello ${ }^{3}$ \\ ${ }^{1}$ Nuclear Medicine Unit Department of Clinical and Experimental Internistic ' $F$. Magrassi, A. \\ Lanzara'- Seconda Università di Napoli Naples, Italy \\ ${ }^{2}$ Department of Biocatalysis and Isotope Chemistry, Almac, 20 Seagoe Industrial Estate, Craigavon, \\ BT63 5QD, United Kingdom \\ ${ }^{3}$ Nuclear Medicine Department, S. Andrea Hospital, La Spezia, Italy
}

*Author to whom correspondence should be addressed:

Luigi Mansi, M.D.

luigi.mansi@unina2.it

\begin{abstract}
This manuscript is a complementary article to an accompanying paper, published in a forthcoming issue, which will give an overview on the central role of chelation in labelling radiocompounds; either for imaging and/or for radionuclide therapy. In order to facilitate a better understanding of the importance of Chelator-Based Imaging \& Therapy, we will briefly discuss in this publication - which is partially intended as an introduction to the second paper - which contains the major basic principles of molecular imaging and radionuclide therapy. Although these issues are of interest in the general field of Nuclear Medicine; since the chelation process involves the labelling with radiometals; we aim to highlight examples of this category in this paper which concern this class of nuclides in this particular issue.
\end{abstract}


Keywords: molecular imaging; radionuclide therapy; radiotracers; chelation; radiometals; radiohalogens; SPECT imaging; PET imaging

\section{Introduction}

The Brookhaven National Laboratory (BNL) developed the first ${ }^{99} \mathrm{Mo} /{ }^{99 \mathrm{~m}} \mathrm{Tc}$ generator in 1959 . This was a most important tool, which gave the possibility to produce in loco radiocompounds usable in the clinical setting [1]. Numerous generator systems have been produced but none have found a commercial diffusion (Table 1). In 1964, the first technetium-99m $\left({ }^{99 m} \mathrm{Tc}\right)$ radiotracers were developed at Argonne National Laboratory [2]. Whilst we have the ability to produce incredibly fast diffusion of positron emission tomography (PET) procedures in the beginning of the third millennium, the majority (around $85 \%$ ) of radiopharmaceuticals used worldwide today in imaging, still contain the radiometal technetium-99m [3].

\begin{tabular}{|c|c|c|c|c|c|c|}
\hline \multirow{2}{*}{$\begin{array}{l}\text { GENERATOR } \\
\text { SYSTEM }\end{array}$} & \multicolumn{3}{|c|}{ PARENT ISOTOPE } & \multicolumn{3}{|c|}{ DAUGHTER ISOTOPE } \\
\hline & $\mathbf{T}_{1 / 2}$ & $\begin{array}{ll}\text { Main Production } \\
\text { Route }\end{array}$ & $\begin{array}{l}\text { Main } \\
\text { Decay }\end{array}$ & $\mathbf{T}_{1 / 2}$ & $\begin{array}{l}\text { Main } \\
\text { Emission }\end{array}$ & Application \\
\hline${ }^{99} \mathrm{Mo}-{ }^{99 m}$ Tc & $66 \mathrm{~h}$ & Reactor & $\beta-$ & $6.006 \mathrm{~h}$ & $\gamma$ & SPECT \\
\hline${ }^{68} \mathrm{Ge}-{ }^{68} \mathrm{Ga}$ & $270.8 \mathrm{~d}$ & Accelerator & $\mathrm{EC}$ & $1.135 \mathrm{~h}$ & $\beta+$ & PET \\
\hline${ }^{62} \mathrm{Zn}-{ }^{62} \mathrm{Cu}$ & $9.26 \mathrm{~h}$ & Accelerator & $\mathrm{EC}$ & $9.74 \mathrm{~m}$ & $\beta+$ & PET \\
\hline${ }^{44} \mathrm{Ti}-{ }^{44} \mathrm{Sc}$ & $47.3 \mathrm{y}$ & Accelerator & $\mathrm{EC}$ & $3.927 \mathrm{~h}$ & $\beta+$ & PET \\
\hline${ }^{90} \mathrm{Sr}-{ }^{90} \mathrm{Y}$ & $28.5 \mathrm{y}$ & Reactor & $\beta-$ & $2.671 \mathrm{~d}$ & $\beta-$ & RT \\
\hline${ }^{225} \mathrm{Ac}-{ }^{213} \mathrm{Bi}$ & $10.0 \mathrm{~d}$ & $\begin{array}{l}\text { Decay chain, } \\
\text { Accelerator }\end{array}$ & $\alpha$ & $45.6 \mathrm{~m}$ & $\alpha, \beta-$ & $\mathrm{RT}$ \\
\hline${ }^{229} \mathrm{Th}-{ }^{225} \mathrm{Ac}$ & $7880 y$ & Decay chain & $\alpha$ & $10 \mathrm{~d}$ & $\alpha, \beta-$ & RT \\
\hline${ }^{188} \mathbf{W}-{ }^{188} \operatorname{Re}$ & $69.4 \mathrm{~d}$ & Reactor & $\beta-$ & $16.98 \mathrm{~h}$ & $\beta-$ & RT \\
\hline${ }^{134} \mathrm{Ce}-{ }^{134} \mathrm{La}$ & $3.16 \mathrm{~d}$ & Accelerator & $\mathrm{EC}$ & $6.4 \mathrm{~m}$ & $\beta+$ & PET \\
\hline${ }^{140} \mathrm{Nd}-{ }^{140} \mathrm{Pr}$ & $3.37 \mathrm{~d}$ & Accelerator & $\mathrm{EC}$ & $3.39 \mathrm{~m}$ & $\beta+, \mathrm{Ae}$ & PET \\
\hline${ }^{166} \mathrm{Dy}-{ }^{166} \mathrm{Ho}$ & $3.40 \mathrm{~d}$ & Reactor & $\beta-$ & $26.80 \mathrm{~h}$ & $\beta-$ & RT \\
\hline${ }^{212} \mathrm{~Pb}-{ }^{212} \mathrm{Bi}$ & $10.64 \mathrm{~h}$ & Decay chain & $\beta-$ & $60.6 \mathrm{~m}$ & $\beta-, \alpha$ & $\mathrm{RT}$ \\
\hline
\end{tabular}

Abbreviations: EC (Electron Capture); Ae (Auger Electron); SPECT (Single Photon Emission Computed Tomography); PET (Positron Emission Tomography), RT (Radiation Therapy).

Table 1: Radionuclide Generator Systems.

Subsequently, radiolabelled imaging agents may be used as radiotracers, having the capability to follow the most important molecular, biochemical and physiological processes that constitute life [47]. In this sense, the radiolabelled imaging agent may detect and evaluate the disease state as a molecular/pathophysiological alteration [8-11]. This approach can be exploited in all of the most 
significant pathological fields with the potential to detect and/or biologically characterize issues such as organ function, tumour malignancy, blood flow alterations, metabolic processes, in vivo receptor distribution and so forth [12-15].

In addition, as well as being used as a diagnostic tool, radiopharmaceuticals also find applications in therapy - notably in the treatment of cancer. However, the clinical application in benign diseases are widely diffuse [16,17]. The Imaging Periodic Table (Table 2) gives an overview of the types of radiation emitted from the various radionuclides.

\begin{tabular}{|c|c|c|c|c|c|c|c|c|c|c|c|c|c|c|c|c|c|c|}
\hline H & \multicolumn{17}{|c|}{ The Imaging Periodic Table } & $\mathrm{He}$ \\
\hline \multirow[t]{2}{*}{$\mathbf{L i}$} & \multirow[t]{2}{*}{$\mathbf{B e}$} & \multirow{3}{*}{\multicolumn{11}{|c|}{$\begin{array}{c}\text { Alpha emitters } \alpha \text {; Beta (electron) emitters } \beta \text {-; } \\
\text { Positron emitters } \beta+\text {; Gamma emitters } \gamma ; \\
\text { Auger electrons Ae }\end{array}$}} & \multirow{3}{*}{$\begin{array}{l}\mathbf{B} \\
\mathbf{A l}\end{array}$} & $\mathbf{C}$ & $\mathbf{N}$ & \multirow[t]{2}{*}{$\mathbf{O}$} & $\mathbf{F}$ & \multirow[t]{2}{*}{$\mathrm{Ne}$} \\
\hline & & & & & & & & & & & & & & $\beta+$ & $\beta+$ & & $\beta+$ & \\
\hline $\mathbf{N a}$ & $\mathbf{M g}$ & & & & & & & & & & & & & Si & $\mathbf{P}$ & $\mathbf{S}$ & Cl & $\mathbf{A r}$ \\
\hline \multirow[t]{2}{*}{$\mathbf{K}$} & \multirow[t]{2}{*}{$\mathbf{C a}$} & Sc & \multirow[t]{2}{*}{$\mathbf{T i}$} & \multirow[t]{2}{*}{$\mathbf{V}$} & \multirow[t]{2}{*}{$\mathrm{Cr}$} & \multirow[t]{2}{*}{ Mn } & $\mathbf{F e}$ & $\mathrm{Ce}$ & \multirow[t]{2}{*}{$\mathbf{N i}$} & C & \multirow{2}{*}{\multicolumn{2}{|c|}{$\mathbf{Z n}$}} & Ga & \multirow[t]{2}{*}{ Ge } & As & \multirow[t]{2}{*}{ Se } & $\mathbf{B r}$ & \multirow[t]{2}{*}{$\mathbf{K r}$} \\
\hline & & $\begin{array}{l}\gamma \\
\beta-\end{array}$ & & & & & $\beta-$ & $\beta$ & & $\begin{array}{l}\beta \\
\beta \\
\gamma\end{array}$ & & & $\begin{array}{l}\beta= \\
\beta+ \\
\gamma\end{array}$ & & $\beta-$ & & Ae & \\
\hline \multirow[t]{2}{*}{$\mathbf{R b}$} & \multirow[t]{2}{*}{$\mathbf{S r}$} & $\mathbf{Y}$ & $\mathbf{Z r}$ & \multirow[t]{2}{*}{$\mathbf{N b}$} & \multirow[t]{2}{*}{ Mo } & Tc & $\mathbf{R u}$ & $\mathbf{R I}$ & $\mathbf{P}$ & $\mathrm{A}$ & \multirow{2}{*}{\multicolumn{2}{|c|}{ Cd }} & In & \multirow[t]{2}{*}{ Sn } & \multirow[t]{2}{*}{$\mathbf{S b}$} & \multirow[t]{2}{*}{$\mathbf{T e}$} & I & \multirow[t]{2}{*}{$\mathbf{X e}$} \\
\hline & & $\beta=$ & $\beta+$ & & & $\gamma$ & $\gamma$ & $\begin{array}{l}\gamma \\
\beta\end{array}$ & $\boldsymbol{\beta}$ & $\begin{array}{l}\gamma \\
\beta\end{array}$ & & & $\gamma$ & & & & $\begin{array}{l}\gamma \\
\beta- \\
\text { Ae }\end{array}$ & \\
\hline \multirow[t]{2}{*}{$\mathrm{Cs}$} & \multirow[t]{2}{*}{$\mathbf{B a}$} & $\mathbf{L a}$ & Hf & $\mathbf{T a}$ & $\mathbf{W}$ & $\mathbf{R e}$ & Os & $\mathbf{I r}$ & $\overline{\mathbf{P}}$ & & & $\overline{\mathrm{Hg}}$ & TI & $\mathbf{P b}$ & $\mathbf{B i}$ & Po & $\mathbf{A t}$ & $\mathbf{R n}$ \\
\hline & & & & & & $\begin{array}{l}\gamma \\
\beta-\end{array}$ & & & & & & & & $\begin{array}{l}\boldsymbol{\beta}- \\
\mathrm{Ae}\end{array}$ & $\alpha$ & & $\boldsymbol{\alpha}$ & \\
\hline $\mathbf{F r}$ & $\mathbf{R a}$ & Ac & & & & & & & & & & & & & & & & \\
\hline & $\alpha$ & $\alpha$ & & & & & & & & & & & & & & & & \\
\hline
\end{tabular}

\begin{tabular}{|l|l|l|l|l|l|l|l|l|l|l|l|l|l|}
\hline Ce & Pr & Nd & Pm & Sm & Eu & Gd & Tb & Dy & Ho & Er & Tm & Yb & Lu \\
& & & & $\gamma$ & & & & $\beta-$ & $\beta-$ & & & $\beta-$ & $\beta-$ \\
Th & Pa & U & Np & Pu & Am & Cm & Bk & Cf & Es & Fm & Md & No & Lr \\
\hline
\end{tabular}

Table 2: The Imaging Periodic Table.

When a radiopharmaceutical is introduced into the body, it localises in particular tissue(s) on the basis of a distribution determined by its action as a radiotracer of a biological process. The extent to which this happens is dependent either on the radiocompound and/or on pathophysiological characteristics of the tissue(s) [18]. A specific radiopharmaceutical may be concentrated at the site of a lesion such as a neoplasm; an infective process and/or of a particularly normal tissue. These processes follow molecular events generally typical for uptake within a tissue(s), although rarely pathognomonic [19]. 
The patient can then be scanned in order to image the radioactivity: this generates a real-time imagine of what is happening in the body [20]. A significant advantage of this method over other imaging techniques is that the ponderal amount of radioactive compounds is very small - often nanomolar quantities or less [21,22]. This is a major advantage for use in molecular imaging with respect to the two main systems currently in use such as computed tomography (CT) and magnetic resonance imaging (MRI), when performed with contrast media.

In fact, gadolinium-containing agents or iodinated contrast media are used to enhance and/or modify the image. These imaging agent are administered in millimolar quantities and for these reasons they cannot be used to image many of the most important molecular processes as neurotransmission, metabolism etc. Subsequently, these processes can only be studied using tracers in the order of micro/nanomoles.

Conversely, the possibility of molecular imaging being in direct competition with nuclear medicine by using optical imaging (OI) has the capability to trace all of the most crucial biological events. Nevertheless, being optical imaging based, using light as the source of the image means that it can not be accurately used in vivo in humans to analyse deep organs. This is because light photons are not able to pass through the tissue matter [23].

\section{Pathophysiological Premises to Nuclear Medicine}

Nuclear Medicine is the field in diagnostic imaging where the value of the image is less dependent on the scanner. The radiotracer is used in the clinical context for radionuclide studies. In order to understand this particular concept, a good precedent can derive from the study used for detecting Meckel's diverticulum which is the most frequent cause of bleeding in paediatrics. Nevertheless, at this time the most reliable diagnostic procedure is the planar scintigraphy used with ${ }^{99 \mathrm{~m}} \mathrm{Tc}$ pertechnetate. The major advantage of planar scintigraphy is its commercial cost effectiveness per patient over the remaining procedures which include PET, SPECT and other radiological techniques such as ultrasound (US), CT and MRI [24].

Although the spatial resolution of a standard gamma camera is typically more than $1 \mathrm{~cm}$, the scintigraphy is able to detect the area of gastric ectopic mucosa at level of the bowel. Also, it may establish the pathophysiological cause of the bleeding. In fact, the radiotracer used for example ${ }^{99 \mathrm{~m}} \mathrm{Tc}-$ pertechnetate, is biologically analogous of iodine. The imaging agent ${ }^{99 \mathrm{~m}} \mathrm{Tc}$-pertechnetate concentrates in thyroid, salivary gland, choroid plexus and gastric mucosa. This behaviour leads to a diagnosis based on a radiotracer's concentration at the level of the ectopic gastric tissue. This allows diagnosis which is not normally feasible by morphostructural techniques not with standing their higher spatial resolution.

This means that in presence of an increased uptake of the radiotracer which would have a favourable lesion/background concentration rate, the information is substantially independent of the spatial resolution from the diagnostic instrument. 
This peculiarity is associated with the so called functional studies, for example in nuclear medicine functional techniques such as Rx, CT, MRI and US, with or without contrast media; in which the image is dependent on a pathophysiological premise, and is not only expression by differences in density as in morphostructural studies.

In other words, these functional studies represent the 'living function': normal (physiology) or altered (pathophysiology). Conversely, morphostructural techniques are used to evaluate 'anatomy' and 'pathological data', i.e. static information having substantially the same content in the living body and/or in a non-living subject.

Furthermore, these functional alterations precede the establishment of a pathological change, as in the non-living subject. Therefore, it is possible to acquire functional procedures with an earlier diagnosis, being achievable original information being more strictly connected with prognosis and therapy [25].

\section{Gamma Emitters and SPECT Imaging}

There is a broad spectrum of radionuclides and between them a large number of radiometals are currently being used for medical imaging and therapy. They have different mechanisms of radioactive decay, making them suitable for particular applications [26]. The most commonly used diagnostic tool involves radiometals which emit gamma rays. The gamma rays are detected using a gamma camera [27]. Typically, this system is based on a detector capturing the rays with a sodium iodide crystal; light photons obtained by 'scintillation' are then transformed into electric signals, amplified and elaborated in order to create an image.
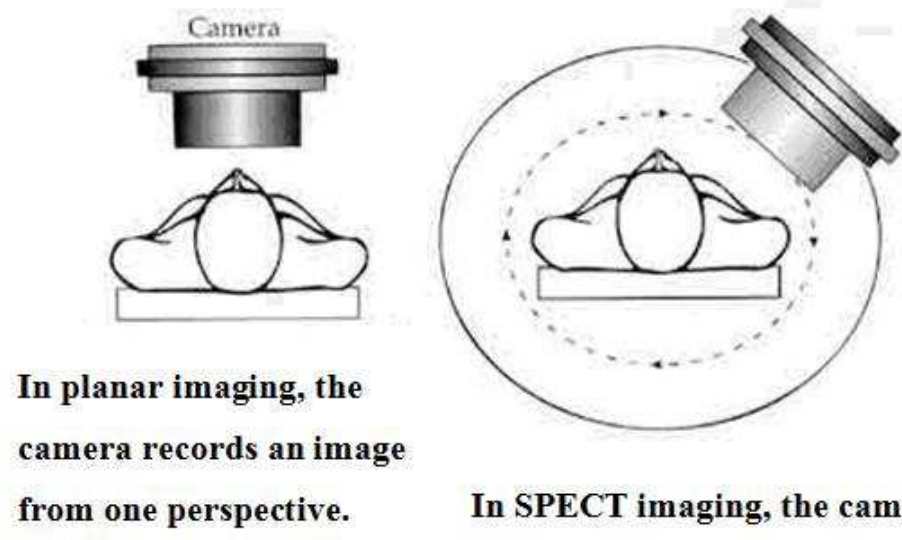

In SPECT imaging, the camera rotates around the patient, recording multiple images that are then reconstructed into a 3-D data set by the computer.

Figure 1: A schematic diagram of SPECT Imaging. 
A similar process is maintained when using more modern detecting systems, as those using solid detectors [28]. Historically created as analogical machines; at the present all gamma cameras are fully digitalized. The final image may be either reconstructed in a single plane, to obtain the so called static or sequential 'scintigraphy', or three-dimensionally, using a single photon emission computed tomography (SPECT) being able to produce a tomoscintigraphy with gamma emitters, i.e. a SPECT image (Figure 1).

A further significant improvement has been achieved with the diffusion of the so called hybrid systems; constructed in the same gantry with two (or exceptionally three) different imaging tools. Typically, a nuclear medicine machine [29] such as (SPECT, PET) combined with a CT scanner [30]. More recently, PET/MRI hybrid systems have been commercialized [31,32], although still in the experimental preclinical field SPECT/MRI machines are still being commercially developed [33].

The major advantage of hybrid machines is the possibility of integrating the functional image obtained by radionuclide procedures with morphostructural data acquired by CT (or MRI). In this instance a significant improvement in diagnostic accuracy is reached; together with further and/or better capabilities, as those connected with a utilization of the hybrid system as a guide for a biopsy or in the better biological definition of a target for radiotherapy. It has to be pointed out that at present all the CT scanners included in a hybrid machine are diagnostic multi-slice CT (MSCT) [34].

Scintigraphy and SPECT are the final result of a signal starting from radionuclides that emit gamma photons of a given energy [35]. In Table 3 are represented the actually more frequently used gamma emitters.

It is noted that, between them, the most diffuse is certainly ${ }^{99 \mathrm{~m}} \mathrm{Tc}$, which utilized in more than $95 \%$ of the examinations performed with a gamma camera. The use of ${ }^{67} \mathrm{Ga}$, as citrate [36], is nearly disappeared, having being completely overwhelmed by the clinic explosion of PET with ${ }^{18}$ F-fluorodeoxyglucose $\left({ }^{18} \mathrm{FDG}\right)$.

The diagnostic use of iodine-131, which emits beta radiation [37] is used in radionuclide therapy and is almost only limited to the whole body evaluation performed in the follow up of patients with differentiated thyroid cancer [38]. In this instance, as in all the other clinical indications where radioiodinated compounds are of diagnostic interest, iodine-123 which is a pure gamma emitter shows more favourable physical and dosimetric characteristics is preferred [39].

Iodine-123 has great potential in radiochemistry, allowing for production of numerous radiopharmaceuticals of clinical interest. Unfortunately radiotracers labelled with iodine-123 are affected by financial constraints which are determined by the need of long distance transport from the few 'industrial' sites of production [40]. 


\begin{tabular}{cccc}
\hline ISOTOPE & DECAY MODE & $\mathbf{T}_{\mathbf{1 / 2}}$ & $\mathbf{E}_{\boldsymbol{\gamma}}[\mathbf{k e V}](\boldsymbol{\%})$ \\
\hline${ }^{{ }^{99} \mathbf{m}} \mathbf{T c}$ & $\mathrm{IT}$ & $6.01 \mathrm{~h}$ & $140.5(87.7)$ \\
${ }^{123} \mathbf{I}$ & $\mathrm{EC}$ & $13.2 \mathrm{~h}$ & $159.0(83.3)$ \\
${ }^{131} \mathbf{I}$ & $\beta-$ & $8.02 \mathrm{~d}$ & $364.5(81.2)$ \\
${ }^{\mathbf{6 7}} \mathbf{G a}$ & $\mathrm{EC}$ & $78.3 \mathrm{~h}$ & $93.3(37)$ \\
& & & $184.6(20.4)$ \\
& & & $300.2(16.6)$ \\
${ }^{111} \mathbf{I n}$ & $\mathrm{EC}$ & $67.4 \mathrm{~h}$ & $245.4(94)$ \\
& & & $171.3(90.3)$ \\
\hline
\end{tabular}

Table 3: A selection of SPECT radionuclides.

The radio-iodinated compounds used in the clinical setting compared to technetium- $99 \mathrm{~m}$ are ${ }^{123} \mathrm{I}$ metaiodobenzylguanidine (MIBG) [41,42] and ${ }^{123}$ I-FP-CIT-ioflupane (DATscan@) [43]. While thallium-201, formerly widely used in myocardial scintigraphy [44], has practically disappeared from the radionuclide toolbox; it is almost completely replaced by technetium-99m perfusion agents. Indium-111 continues to be utilized almost exclusively for the labelling of the somatostatin analogue octreotide (Octreoscan $\odot)$ [45].

\section{Molecular Imaging Capabilities of Gamma Emitters and SPECT}

Radiocompounds labelled with technetium-99m are the most diffuse radiotracers used in clinical practice; due to their ability to perform in widely used studies, as gated-SPECT with myocardial perfusion agents, bone scans, thyroid scintigraphy and so forth [46-51]. In conjunction with traditional examinations, nethertheless there is a role, shared by iodine-123 radiotracers, already available in the clinical setting.

Consequently developing innovative applications, as those more strictly related to a molecular imaging based on complex pathophysiological premises; for example it is already possible to image metabolic pathways and receptor expression.

In this context, the information generated from molecular imaging is able to uncover staging and monitor numerous cancers, ability to detect and biologically-time deep venous thrombosis (DVT). In addition, molecular imaging would have the potential to evaluate multi-drug resistance to chemotherapy including imaging angiogenesis and apoptosis. Molecular imaging has the ability to target early diagnosis of disease states and to calculate the therapeutic response from novel biological drugs. Finally, molecular imaging would help to diagnose and evaluate Parkinson's disease and other neurodegenerative conditions in the clinical setting [52]. 


\section{PET Imaging}

Presently, positron emission tomography (PET) is the technological apex of radionuclide imaging techniques in humans, providing the highest sensitivity and spatial resolution. This innovative procedure arrived in the 1970's and was applied first in the early 1980's, mainly for the evaluation of brain diseases. Accordingly, PET is actually worldwide diffuse, prominent in oncology amongst other clinical indications, such as those concerning patients with cerebral, inflammatory and cardiac diseases, which are also present [53-56].

However, when certain radionuclides decay, a positron (a positively charged nuclear particle with the same mass as an electron) is emitted from the nucleus (Figure 2).
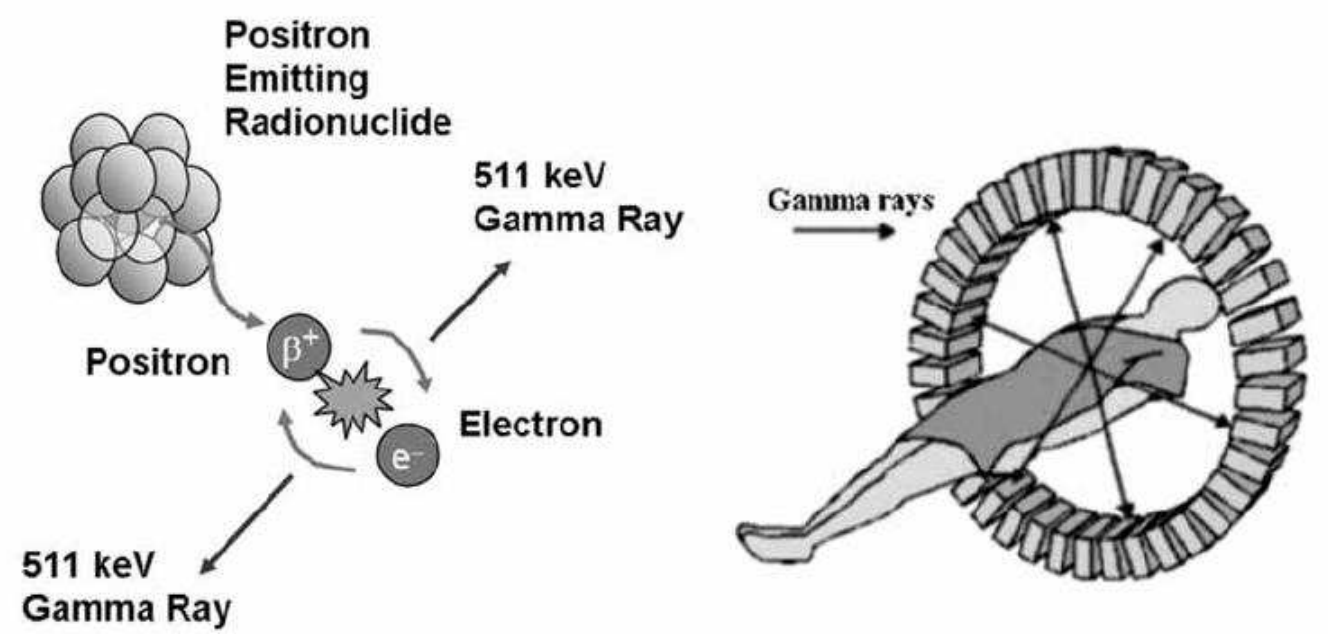

Figure 2: A schematic diagram of PET Imaging.

This positron $(\beta+)$ collides with an electron $\left(\mathrm{e}^{-}\right)$and both particles are annihilated, releasing energy $(511 \mathrm{keV})$ in the form of two gamma rays, travelling in opposite directions. A series of detectors are placed around the subject, allowing for both the location and measurement of amounts of radioactivity in the patient to be determined more accurately than is possible with SPECT imaging. Whilst utilizing gamma emitters, it is possible to achieve planar images. Positron emitters are solely utilized to produce a tri-dimensional reconstruction, i.e. a tomography.

As for SPECT, a significant improvement may be clinically achieved using hybrid machines. At present, these are commercially available PET/CT and PET/MRI systems are available. Furthermore, because of the 'proof of concept' and superiority of all the PET machines they are now sold as hybrids i.e. PET/CT and no longer manufacture the stand-alone PET equipment. The most diffuse positron emitters are reported in Table 4. 


\section{ISOTOPE $\mathbf{T}_{1 / 2}[\mathrm{~min}] \mathbf{E}_{\beta+\max }[\mathrm{MeV}]$ Maximum range in water $[\mathrm{mm}]$}

\begin{tabular}{c|ccc}
\hline${ }^{\mathbf{1 1}} \mathbf{C}$ & 20.38 & 1.0 & 4.1 \\
\hline${ }^{\mathbf{1 3}} \mathbf{N}$ & 9.96 & 1.2 & 5.4 \\
${ }^{\mathbf{1 5}} \mathbf{O}$ & 2.03 & 1.7 & 8.2 \\
${ }^{\mathbf{1 8}} \mathbf{F}$ & 109.7 & 0.6 & 2.4 \\
\hline${ }^{\mathbf{6 8}} \mathbf{G a}$ & 67.6 & 1.9 & 10.0 \\
${ }^{\mathbf{8}} \mathbf{R} \mathbf{b}$ & 1.27 & 3.3 & 20 \\
\hline
\end{tabular}

Table 4: A selection of PET positron emitters.

\section{Molecular Imaging Capabilities of PET}

In the toolbox of functional techniques PET occupies a primary role. As previously reported the PET scanner is the technological apex of the current arsenal of Nuclear Medicine machines available today. This is because PET alone offers the best sensitivity and spatial resolution. In addition, the main reason of its importance is outlined in Table 4. These positron emitters consists of the radionuclides carbon11 , nitrogen-13 and oxygen-15; i.e. radioisotopes of three of the major constituents of biological matter.

Unfortunately, these radionuclides are affected by a too fast physical half-life - in the order of few minutes - their clinical utilization requires the in loco availability of a cyclotron, i.e. of the production machine. This creates difficult organizational problems. As a result of the radionuclides having a rapid half-life and for these reasons, the real birth, growth and diffusion of the clinical role of PET has been dependent on fluorine-18, having a longer half-life (110 minutes). This allows for its use also in centres without cyclotrons.

Accordingly, fluorine-18 is a radio-halogen having the capability of radiolabelling, without modifying its biochemical functionality. Fundamental biomolecules, which can be first of all the utilized, include the glucose analogue 2-deoxy-2- $\left({ }^{18}\right.$ F)fluoro-D-glucose $\left({ }^{18}\right.$ FDG $)$.

Furthermore, using this radiopharmaceutical, it is possible to study in vivo pathophysiological changes which occur in humans during glucose metabolism which typically is increased in the large majority of malignant neoplasm as well as in some benign pathologies, such as active inflammatory diseases $[57,58]$. The commercial availability of ${ }^{18} \mathrm{FDG}$ is present in numerous a Nuclear Medicine Institutions and its major clinical role is to help in the diagnosis of cancer disease states (Table 5).

PET $-{ }^{18} \mathrm{FDG}$ is rapidly growing as the number of radio-fluorinated compounds, including many newer radiopharmaceuticals such as ${ }^{18} \mathrm{~F}-\mathrm{DOPA} \quad\left(\left[{ }^{18} \mathrm{~F}\right]-6\right.$-fluoro- $L$-3,4-dihydroxyphenylalanine), ${ }^{18} \mathrm{~F}-$ florbetapir/flutemetamol/florbetaben and other amyloid radiotracers, ${ }^{18} \mathrm{~F}$-fluorocholine $\left({ }^{18} \mathrm{FCH}\right), 3{ }^{\prime}$ deoxy-3'-[ $\left.{ }^{18} \mathrm{~F}\right]$ fluorothymidine $\left({ }^{18} \mathrm{FLT}\right)$. 


\section{ONCOLOGY}

CARDIOLOGY

- PET can be used to assess the presence, extent and severity of cardiovascular disease, especially coronary artery disease (CAD).

- Its role is particularly centred on the evaluation of viable myocardium.

- PET helps to identify patients who are likely to benefit from heart bypass surgeries and/or other revascularization interventions.
- The most important applications are its ability to re-stage and stage a large number of malignancies such as lymphoma, cancers of breast, colon, lung etc. at a phase when conventional imaging tools frequently fail to do so.

- May be a useful technique in differentiating malignant from benign lesions.

- May help in locating the best site for biopsy of a suspected tumour or in defining the biological target for Radiotherapy.

- May allow a prognostic stratification which is useful in individuating de-differentiation in follow up of patients with well differentiated tumours.

- It is useful in monitoring the effects of therapy (radiation, chemotherapy, amongst other approaches).

- It is able to detect the sites of recurrent disease and differentiate it from radiation or post-surgical tissue necrosis.
NEUROLOGY

- PET is useful in diagnosis, planning treatment and predicting outcomes in various neurological diseases such as Alzheimer's disease.

\section{INFLAMMATION}

\section{OTHER BENIGN} PATHOLOGIES
- May define activity of inflammatory diseases such as granulomatosis, sarcoidosis, tuberculosis, arteritis and Crohn's disease.

- May allow diagnosis of acute or chronic infection/inflammation.

- In the Fever of Unknown Origin (FUO) it may detect the pathologic site, (more frequently a lymphoma or a chronic inflammation).

- May define functional activity at the level of benign lesions, mainly in endocrinology.

Table 5. Some of the most important clinical indications for PET $-{ }^{18}$ FDG. 
With respect to the three 'major' radionuclides expressing a too fast half-life (i.e. ${ }^{11} \mathrm{C},{ }^{13} \mathrm{~N}$ and ${ }^{15} \mathrm{O}$ ), it is paramount that the cyclotron is close to the PET scanner. However, the use a cyclotron is currently limited to the research field. Accordingly, the clinical application of a PET scanner is only available when the facilities include a cyclotron and a qualified radiopharmacy. However, clinical usage is restricted to a few radiocompounds such as ${ }^{11} \mathrm{C}$-choline, ${ }^{11} \mathrm{C}$-methionine and ${ }^{13} \mathrm{~N}$-ammonia.

In industry, the general policy supports, when possible the production and use of alternative radiofluorinated compounds. This is already happening for ${ }^{18} \mathrm{~F}$-choline and for amyloid radiotracers [59]. There is great interest in the clinical practice directed towards the diffusion of generator systems producing gallium- 68 or rubidium- 82 .

The clinical value of the ${ }^{68} \mathrm{Ge} /{ }^{68} \mathrm{Ga}$ generator systems will be discussed in the following paper (part 2). This is mainly connected with the possibility of labelling somatostatin analogues [60]. The ${ }^{82} \mathrm{Sr} /{ }^{82} \mathrm{Rb}$ system produces the potassium analogue ${ }^{82} \mathrm{Rb}$-chloride which allows quantitative cardiac studies. The diffusion of this ${ }^{82} \mathrm{Sr} /{ }^{82} \mathrm{Rb}$ is partially counterbalanced by the high cost/effectiveness in the clinical field of the alternative radionuclide study, i.e. gated SPECT with technetium-99m perfusion agents [61].

The positron emitting radioisotope of iodine, i.e. iodine-124, is absent from Table 4 . This is due to a lack of interest for this radionuclide because its half-life of 4.18 days is too high. This makes it clinically problematic as there are issues with dosimetry and also the management of radioactive waste. Consequently, whilst some scientific papers can be found in literature; a discussion of iodine124 as a gold standard for patients with differentiated thyroid cancer. Nevertheless, in the clinical context iodine-124 is not a competitive cost/effective alternative with respect to the corresponding gamma emitter for example iodine-123.

\section{PET Molecular Imaging}

PET in humans provides the most effective spatial resolution and sensitivity amongst all the alternative radionuclide techniques. Furthermore, it is possible to radiolabel with positron emitters practically all the most important molecules of biological interest [62]. Therefore, it is clear that PET, either as the hybrids PET/CT or PET/MRI, represents the most efficient way in humans to generate molecular images. Moreover, having the capability to determine an earlier diagnosis and/or to acquire pathophysiological information more strictly connected with prognosis and therapy [63].

Consequently, the analysis of molecular imaging is not the aim of this paper we only suggest here some references that could give to the reader a sufficient although updated information [64].

\section{Beta Particles}

A third type of radioactive decay involves the emission of a nuclear beta particle having the mass of an electron and being negatively charged. Several of these radionuclides are used in radionuclide therapy, because these particles have the ability to travel a short distance in biological tissues. Hence, producing 
ionization events and localized damage in a distance of microns up to few millimetres from the point of origin [65]. This ensures that biologically damaging collisions between the particle and cellular components mainly occur close to where the radiopharmaceutical has localised, thus reducing the damage to healthy tissues due to limited concentration of the radionuclide.

However, due to the crossfire effect, aneoplastic or otherwise pathological non-concentrating cells may be destroyed, if they stand within the maximum range of the beta radiation [66].

More recently, new radiobiological effects have been proposed to justify the possibility to kill pathological cells that do not concentrate the radionuclide. The first is the so called bystander effect which determines the possible killing of cells without targeting the residents in the pathophysiological unit where the therapeutic radiocompound has been concentrated by targeted cells. This destructive action is probably connected with toxic molecules, produced through the destructive effect of radiations and released into the extracellular space.

The second mechanism is called abscopal effect and may determine the possible destruction of nonconcentrating cells also far from the site of the radioactive's uptake, as in distant metastases. This phenomenon is probably connected with the activation of the immune system against neoplastic cells, probably involving T-cells and dendritic cells.

With respect to the range of their direct ionizing effect beta radiations may be categorized by:

- Low-range beta sources (mean range $<200 \mu \mathrm{m}$ ). Nuclides of this category may provide a uniformity of local energy deposit substantially comparable with alpha emitters.

- Medium-range beta sources $(200 \mu \mathrm{m}<$ mean range $<0.2-1.0 \mathrm{~mm})$. Possible medium range beta sources include ${ }^{47} \mathrm{Sc},{ }^{67} \mathrm{Cu},{ }^{77} \mathrm{As},{ }^{105} \mathrm{Rh},{ }^{109} \mathrm{Pd},{ }^{111} \mathrm{Ag},{ }^{131} \mathrm{I},{ }^{161} \mathrm{~Tb}$ and ${ }^{186} \mathrm{Re}$.

- Long-range beta sources (mean range $>1 \mathrm{~mm}$ ). Candidates include ${ }^{32} \mathrm{P},{ }^{90} \mathrm{Y}$ and ${ }^{188} \mathrm{Re}$.

It has to be remembered that radionuclides preferably used in diagnostic imaging are pure gamma emitters. Nevertheless some radionuclides such as ${ }^{131} \mathrm{I}$ or ${ }^{177} \mathrm{Lu}$ have a decay mode which emits both gamma and beta radiations. This characteristic, because of the associated high radiation dose to the patient is ineffective for imaging. Therefore, becomes a negative issue when radiocompounds are labelled with these radionuclides (e.g. ${ }^{131} \mathrm{I}$ or ${ }^{177} \mathrm{Lu}$ ) are proposed for diagnostic purposes [67].

Conversely, when they are used in radionuclide therapy, this peculiarity becomes an advantage, allowing the in vivo visualization of the distribution of the radiotherapeutic compound. In absence of a gamma emission, beta emitters may also be imaged through the so called bremsstrahlung X-ray radiation [68]. 


\section{Alpha Particles}

Alpha particles (Table 6) may be used in therapy to destroy a variety of tumours, but they are not yet widely diffuse in the clinical setting. The appeal of alpha particles is their short range, about 50-90 $\mu \mathrm{m}$ and high linear energy transfer (LET) which is in the order of $80 \mathrm{keV} / \mu \mathrm{m}$. An alpha particle traversing a diameter of a $10 \mu \mathrm{m}$ cell nucleus will deposit energy of $800 \mathrm{keV}$ which is equivalent to an absorbed dose of about 0.25 Gy. Only about 3-6 hits per cell nucleus are required to kill a fraction of $63 \%$ population.

To reach a more favourable cost/effective model for therapeutic purposes will require a high tumour/background ratio. Thus allowing lethal doses to destroy the neoplasm without any significant damage to the surrounding normal cells would be a requirement for this technique.

The potential alpha-emitters for radionuclide therapy and in particular the ability to radiolabel monoclonal antibodies (MoAb) in radioimmunotherapy (RIT) include astatine-211 and bismuth-212. However, bismuth-212 is produced from lead-212 and its half-life $(60.6 \mathrm{~min})$ is too short to be used alone in the clinical setting [69].

\begin{tabular}{|c|c|c|c|c|c|}
\hline Radionuclide & Type & Half-life & $\mathrm{E}_{\max }(\mathrm{MeV})$ & Mean range (mm) & Imageable \\
\hline${ }^{90} \mathbf{Y}$ & $\beta$ & $2.7 \mathrm{~d}$ & 2.3 & 2.76 & No \\
\hline${ }^{131} \mathbf{I}$ & $\beta, \gamma$ & $8.0 \mathrm{~d}$ & 0.81 & 0.40 & Yes \\
\hline${ }^{177} \mathrm{Lu}$ & $\beta, \gamma$ & $6.7 \mathrm{~d}$ & 0.50 & 0.28 & Yes \\
\hline${ }^{153} \mathrm{Sm}$ & $\beta, \gamma$ & $2.0 \mathrm{~d}$ & 0.80 & 0.53 & Yes \\
\hline${ }^{186} \mathrm{Re}$ & $\beta, \gamma$ & $3.8 \mathrm{~d}$ & 1.1 & 0.92 & Yes \\
\hline${ }^{188} \mathrm{Re}$ & $\beta, \gamma$ & $17.0 \mathrm{~h}$ & 2.1 & 2.43 & Yes \\
\hline${ }^{67} \mathrm{Cu}$ & $\beta, \gamma$ & $2.6 \mathrm{~d}$ & 0.57 & 0.6 & Yes \\
\hline${ }^{225} \mathrm{Ac}$ & $\alpha, \beta$ & $10 \mathrm{~d}$ & 5.83 & $0.04-0.1$ & Yes \\
\hline${ }^{213} \mathrm{Bi}$ & $\alpha$ & $45.7 \mathrm{~min}$ & 5.87 & $0.04-0.1$ & Yes \\
\hline${ }^{212} \mathrm{Bi}$ & $\alpha$ & $1.0 \mathrm{~h}$ & 6.09 & $0.04-0.1$ & Yes \\
\hline${ }^{211} \mathrm{At}$ & $\alpha$ & $7.2 \mathrm{~h}$ & 5.87 & $0.04-0.1$ & Yes \\
\hline${ }^{212} \mathrm{~Pb}$ & $\beta$ & $10.6 \mathrm{~h}$ & 0.57 & 0.6 & Yes \\
\hline${ }^{125} I$ & Auger & $60.1 \mathrm{~d}$ & 0.35 & $0.001-0.02$ & Yes \\
\hline${ }^{123} I$ & Auger & $13.2 \mathrm{~h}$ & 0.16 & $0.001-0.02$ & No \\
\hline${ }^{67} \mathbf{G a}$ & Auger & $3.3 \mathrm{~d}$ & 0.18 & $0.001-0.02$ & Yes \\
\hline${ }^{196 m} \mathrm{Pt}$ & Auger & $4.0 \mathrm{~d}$ & 0.13 & $0.001-0.02$ & No \\
\hline
\end{tabular}

Table 6: Shows the most important therapy radionuclides used in nuclear medicine.

Nevertheless, if a lead-212 radiolabelled MoAb conjugation (the basis of a pro-drug) can be formed the lead-212 will continuously generate bismuth-212 acting on the tumour cells. Although less interesting from a radiochemical perspective, the first alpha emitter which appeared in the clinical setting was radium-223 and indicated similar pharmacokinetics to calcium [70]. 
Therefore, lead-212 radiolabelled MoAb conjugations have been proposed in the palliative/curative therapy of patients with advanced prostate cancer and diffuse skeletal metastatic cancers [71].

In fact, because of the high osteoblastic activity at the level of the secondary neoplastic lesions, it is possible to give a high radiation dose to the bone metastases, in presence of a satisfactory salvage of adjacent bone marrow normal cells.

\section{Electron Capture (EC) and Internal Conversion (IC)}

In electron capture (EC) and internal conversion (IC) decaying sources, gamma rays and a copious flux of Auger electrons (Ae) are released. Most of the Auger electrons emitted are of very short range $(<1$ $\mu \mathrm{m})$ and therefore are only of therapeutic importance if the source is attached or localized very close to the target DNA. However, with internal conversion (IC), an electron of high energy may be released [72].

Radionuclides which have EC or IC decay mechanism can be utilized in radiolabelling of monoclonal antibodies. These radionuclides are linked to the monoclonal antibody by using bifunctional chelating agents such as derivatives of DTPA. The radionuclides such as ${ }^{111} \mathrm{In}$ and to a lesser extent, ${ }^{99 \mathrm{~m}} \mathrm{Tc},{ }^{90} \mathrm{Y}$, ${ }^{67} \mathrm{Ga},{ }^{68} \mathrm{Ga},{ }^{109} \mathrm{Pd},{ }^{46} \mathrm{Sc},{ }^{186} \mathrm{Re},{ }^{212} \mathrm{Bi}$ and ${ }^{169} \mathrm{Yb}$ have been used to label numerous peptides and proteins [73].

Conversely, after the initial application of ${ }^{111}$ In-pentreotide (Octreoscan@) at high dosage in patients with neuroendocrine tumours (NET), this approach didn't generate a further significant scientific and/or commercial interest, because of the superiority of alternative strategies [74,75].

\section{Conclusion}

In this paper we have briefly described the basic premises to molecular imaging and radionuclide therapy, i.e. the core of Nuclear Medicine. The future of imaging agents is very dependent on radiochemical methodologies being developed to allow the incorporation of the radionuclide into the chemical compound.

In particular, it is very important to comprehend the capability of radionuclide procedures to act as primary tools either in molecular imaging and/or in a therapy based on pathophysiological premises. In the accompanying paper, Chelator-Based Imaging \& Therapy, the radiochemical issues of radiochelates will be more extensively reviewed. For diagnostic purposes, the gamma emitting metal technetium-99m still remains the most diffuse worldwide clinically used radionuclide. Its pivotal role in radiochemistry strongly stimulates an experimental and commercial interest in individuating new radiochelates, having capability to enlarge the borders of the use of SPECT, mainly in the most modern applications of molecular imaging.

The advancement of chemical synthesis will allow further diffusion of positron emitters in the clinical setting and to develop more interesting PET imaging agents which go beyond ${ }^{18}$ FDG. In this context, 
together with the broader interest for novel radiofluorinated compounds, a major attention is certainly directed to the development of radiopharmaceuticals that could be labelled with gallium-68 produced from mobile generator systems.

Concerning the area of radiochelates is to generate a greater interest in radiocompounds which can be utilized for therapeutic purposes. In fact, it has to be remembered that all radiopharmaceuticals may undergo an in vivo metabolic process, producing new useless and harmful radiochemical metabolite(s). While only a minor negative effect is generally determined when using diagnostic tools, it can be detrimental when unstable radiocompounds are used for radiotherapeutic purposes. Therefore, although a therapeutic effect may be carried out with beta emitters and in some cases allow the radiolabelling of many complex biomolecules. In particular, iodine-131, but unfortunately the high in vivo rate of de-iodination is a major drawback for the predictable achievement of a favourable tumour/background ratio for a large number of radio-iodinated therapeutic tools.

Conversely, radiochelation allows the production of many stable radiocompounds which frequently remains largely unmetabolized when injected in vivo. Therefore, although the presence of collateral effects, as those connected with the possible high radiation dose at the level of emunctories or bone marrow, may limit the dosage, their in vivo efficacy may be more easily predicted, using pharmacokinetics dosimetric models.

This capability strongly stimulates either a basic and applied research of commercial interest, which concerns the synthesis of many new 'radiotherapeutic bullets', including many of the most modern and intriguing biopharmaceuticals. In this context, the technological drive is to produce radiopharmaceuticals which can be labelled not only with beta emitters, but also with the more effective, although yet less manageable, alpha emitters. Therefore, the pivotal role in radiochemistry of radio-halogens, such as radioiodine and fluorine-18, will certainly remain in the near future. Furthermore, the interest for radiolabelling with metals using chelates will similarly grow either for diagnostic and/or therapeutic purposes.

\section{Conflicts of Interest}

The authors confirm that this article has no conflicts of interest.

\section{References}

Key Article References: 7, 9, 17, 19, 26, 30, 53, 58, 68 \& 69

[1] Powell R. A survey of the production at Brookhaven National Laboratory of radioisotopes for medical research. VII Rassegna Internazionale Elettronica e Nucleare Roma. 1960: 223-244.

[2] Richards P, Tucker WD, Srivastava SC. Technetium-99m: an historical perspective. Int J Appl Radiat Isot. 1982; 33(10):793-799. [CrossRef] [PubMed Abstract]

[3] Eckelman WC. Unparalleled contribution of technetium-99m to medicine over 5 decades. JACC Cardiovasc Imaging. 2009; 2(3): 364-368. [CrossRef] [PubMed Abstract] 
[4] Pappatà S, Salvatore E, Postiglione A. In vivo imaging of neurotransmission and brain receptors in dementia. J Neuroimaging. 2008; 18(2): 111-124. [CrossRef] [PubMed Abstract]

[5] Nandhagopal R, McKeown MJ, Stoessl AJ. Functional imaging in Parkinson disease. Neurology. 2008; 70(16 Pt 2): 1478-1488. [PubMed Abstract]

[6] Acampa W, Di Benedetto C, Cuocolo A. An overview of radiotracers in nuclear cardiology. $J$ Nucl Cardiol. 2000;7(6):701-707. [CrossRef] [PubMed Abstract]

[7] Botelho MF, Abrantes AM. Radiotracers in oncology. Curr Radiopharm. 2012; 5(2): 79-89. [PubMed Abstract]

[8] Cuccurullo V, Cascini G, Rossi A, Tamburrini O, Rotondo A, Mansi L. Pathophysiological premises to radiotracers for bone metastases. Q J Nucl Med Mol Imaging. 2011; 55(4): 353 373. [PubMed Abstract]

[9] Cuccurullo V, Cascini GL, Tamburrini O, Rotondo A, Mansi L. Bone metastases radiopharmaceuticals: an overview. Curr Radiopharm. 2013; 6(1): 41-47. [CrossRef] [PubMed Abstract]

[10] Gomes CM. Cationic lipophilic radiotracers for functional imaging of multidrug resistance. Curr Radiopharm. 2012; 5(2): 113-123. [PubMed Abstract]

[11] Virgolini I, Traub T, Leimer M et al. New radiopharmaceuticals for receptor scintigraphy and radionuclide therapy. Q J Nucl Med. 2000; 44(1): 50-58. [PubMed Abstract]

[12] Cuccurullo V, Cascini GL, Mansi L. Structural, pathophysiological and clinical aspects of diagnostic imaging in breast recurrence: the breast after treatment. Q J Nucl Med Mol Imaging. 2013; 57(4): 322-331. [PubMed Abstract]

[13] Cascini GL, Cuccurullo V, Tamburrini O, Rotondo A, Mansi L. Peptide imaging with somatostatin analogues: more than cancer probes. Curr Radiopharm. 2013; 6(1): 36-40. [PubMed Abstract]

[14] Cuccurullo V, Faggiano A, Scialpi M, et al. Questions and answers: what can be said by diagnostic imaging in neuroendocrine tumors. Minerva Endocrinol. 2012; 37(4): 367-377. [PubMed Abstract]

[15] Cuccurullo V, Cascini GL, Tamburrini O, Mansi L, Rotondo A. Less frequent requests for In111 pentreotide and its brothers of endocrinological interest. Minerva Endocrinol. 2011; 36(1): 41-52. [PubMed Abstract]

[16] Mansi L, Virgolini I. Diagnosis and therapy are walking together on radiopeptides' avenue. Eur J Nucl Med Mol Imaging. 2011; 38(4): 605-612. [CrossRef] [PubMed Abstract]

[17] Cascini GL, Cuccurullo V, Mansi L. The non tumour uptake of (111)In-octreotide creates new clinical indications in benign diseases, but also in oncology. Q J Nucl Med Mol Imaging. 2010; 54(1): 24-36. [PubMed Abstract]

[18] Grenier N, Brader P. Principles and basic concepts of molecular imaging. Pediatr Radiol. 2011; 41(2): 144-160. [CrossRef] [PubMed Abstract]

[19] Wadsak W, Mitterhauser M. Basics and principles of radiopharmaceuticals for PET/CT. Eur J Radiol. 2010; 73(3): 461-469. [CrossRef] [PubMed Abstract]

[20] Britz-Cunningham SH, Adelstein SJ. Molecular targeting with radionuclides: state of the science. J Nucl Med. 2003; 44(12): 1945-1961. [PubMed Abstract] [Reference Source] 
[21] Mansi L. Nuclear medicine is to Fukushima as drug is to poison: el sueño de la razón produce monstruos. Eur J Nucl Med Mol Imaging. 2012; 39(2): 369-372. [PubMed Abstract]

[22] Chianelli M, Signore A, Mansi L, Salvatori M. Time for radiobiology in the nuclear medicine community. Eur J Nucl Med Mol Imaging. 2011; 38(7): 1267-1269. [CrossRef]

[PubMed Abstract]

[23] Koshy S, Thompson RC. Review of radiation reduction strategies in clinical cardiovascular imaging. Cardiol Rev. 2012; 20(3): 139-144. [CrossRef] [PubMed Abstract]

[24] Kiratli PO, Aksoy T, Bozkurt MF, Orhan D. Detection of ectopic gastric mucosa using ${ }^{99 \mathrm{~m}} \mathrm{Tc}$ pertechnetate: review of the literature. Ann Nucl Med. 2009; 23(2): 97-105. [CrossRef] [PubMed Abstract]

[25] Galli G, Indovina L, Calcagni ML, Mansi L, Giordano A. The quantification with FDG as seen by a physician. Nucl Med Biol. 2013; 40(6): 720-730. [CrossRef] [PubMed Abstract]

[26] Macías MT. Use of radionuclides in cancer research and treatment. Clin Transl Oncol. 2009; 11(3): 143-153. [PubMed Abstract]

[27] Bailey DL, Willowson KP. An evidence-based review of quantitative SPECT imaging and potential clinical applications. J Nucl Med. 2013; 54(1): 83-89. [CrossRef] [PubMed Abstract]

[28] D'Asseler Y. Advances in SPECT imaging with respect to radionuclide therapy. Q J Nucl Med Mol Imaging. 2009; 53(3): 343-347. [PubMed Abstract] [Reference Source]

[29] Basu S, Kwee TC, Surti S, Akin EA, Yoo D, Alavi A. Fundamentals of PET and PET/CT imaging. Ann N Y Acad Sci. 2011; 1228: 1-18. [CrossRef] [PubMed Abstract]

[30] Wadsak W, Mitterhauser M. Basics and principles of radiopharmaceuticals for PET/CT. Eur J Radiol. 2010; 73(3): 461-469. [CrossRef] [PubMed Abstract]

[31] Mansi L, Ciarmiello A, Cuccurullo V. PET/MRI and the revolution of the third eye. Eur J Nucl Med Mol Imaging. 2012; 39(10): 1519-1524. [CrossRef] [PubMed Abstract]

[32] Mansi L, Ciarmiello A. Perspectives on PET/MR imaging: are we ready for clinical use? J Nucl Med. 2014; 55(4): 529-530. [CrossRef] [PubMed Abstract]

[33] Ha S, Hamamura MJ, Roeck WW, Muftuler LT, Nalcioglu O. Development of a new RF coil and gamma-ray radiation shielding assembly for improved MR image quality in SPECT/MRI. Phys Med Biol. 2010; 55(9): 2495-504. [CrossRef] [PubMed Abstract]

[34] Yang CC, Liu SH, Mok GS, Wu TH. Evaluation of radiation dose and image quality of CT scan for whole-body pediatric PET/CT: A phantom study. Med Phys. 2014; 41(9): 092505. [CrossRef] [PubMed Abstract]

[35] Pillai MR, Dash A, Knapp FF Jr. Sustained availability of ${ }^{99 \mathrm{~m}} \mathrm{Tc}$ : possible paths forward. $J$ Nucl Med. 2013; 54(2): 313-323. [CrossRef] [PubMed Abstract]

[36] Basu S, Zhuang H, Torigian DA, Rosenbaum J, Chen W, Alavi A. Functional imaging of inflammatory diseases using nuclear medicine techniques. Semin Nucl Med. 2009; 39(2): 124145. [CrossRef] [PubMed Abstract]

[37] Avram AM. Radioiodine scintigraphy with SPECT/CT: an important diagnostic tool for thyroid cancer staging and risk stratification. J Nucl Med. 2012; 53(5): 754-764. [CrossRef] [PubMed Abstract] 
[38] Wyszomirska A. Iodine-131 for therapy of thyroid diseases. Physical and biological basis. Nucl Med Rev Cent East Eur. 2012; 15(2): 120-123. [PubMed Abstract]

[39] Palaniswamy SS, Subramanyam P. Diagnostic utility of PETCT in thyroid malignancies: an update. Ann Nucl Med. 2013; 27(8): 681-693. [CrossRef] [PubMed Abstract]

[40] Eckelman WC, Bonardi M, Volkert WA. True radiotracers: are we approaching theoretical specific activity with Tc-99m and I-123? Nucl Med Biol. 2008; 35(5): 523-527. [CrossRef] [PubMed Abstract]

[41] Cuccurullo V, Mansi L. Toward tailored medicine (and beyond): the phaeochromocytoma and paraganglioma model. Eur J Nucl Med Mol Imaging. 2012; 39(8): 1262-1265. [CrossRef] [PubMed Abstract]

[42] Treglia G, Stefanelli A, Bruno I, Giordano A. Clinical usefulness of myocardial innervation imaging using Iodine-123-meta-iodobenzylguanidine scintigraphy in evaluating the effectiveness of pharmacological treatments in patients with heart failure: an overview. Eur Rev Med Pharmacol Sci. 2013; 17(1): 56-68. [PubMed Abstract] [Reference Source]

[43] Bajaj NP. Role of DaTSCAN and clinical diagnosis in PD. Neurology. 2012; 78(19): 15381539. [CrossRef] PubMed Abstract]

[44] Vanzetto G, Ormezzano O, Fagret D, Comet M, Denis B, Machecourt J. Long-term additive prognostic value of thallium-201 myocardial perfusion imaging over clinical and exercise stress test in low to intermediate risk patients: study in 1137 patients with 6-year follow-up. Circulation. 1999; 100(14): 1521-1527. [CrossRef] [PubMed Abstract]

[45] Mansi L, Cuccurullo V. Diagnostic imaging in neuroendocrine tumors. J Nucl Med. 2014; 55(10): 1576-1577. [CrossRef] [PubMed Abstract]

[46] Abidov A, Germano G, Hachamovitch R, Slomka P, Berman DS. Gated SPECT in assessment of regional and global left ventricular function: an update. J Nucl Cardiol. 2013; 20(6): 11181143. [CrossRef] [PubMed Abstract]

[47] Talbot JN, Paycha F, Balogova S. Diagnosis of bone metastasis: recent comparative studies of imaging modalities. Q J Nucl Med Mol Imaging. 2011; 55(4): 374-410. [PubMed Abstract]

[48] Joyce JM, Swihart A. Thyroid: nuclear medicine update. Radiol Clin North Am. 2011; 49(3): 425-434. [CrossRef] [PubMed Abstract]

[49] Uliel L, Mellnick VM, Menias CO, Holz AL, McConathy J. Nuclear medicine in the acute clinical setting: indications, imaging findings, and potential pitfalls. Radiographics. 2013; 33(2): 375-396. [CrossRef] [PubMed Abstract]

[50] Love C, Palestro CJ. Radionuclide imaging of inflammation and infection in the acute care setting. Semin Nucl Med. 2013; 43(2): 102-113. [CrossRef] [PubMed Abstract]

[51] Vivier PH, Dolores M, Le Cloirec J, et al. Imaging evaluation of renal function: principles and limitations. J Radiol. 2011; 92(4): 280-290. [PubMed Abstract] [Reference Source]

[52] Ciarmiello A, Giovannini E, Meniconi M, Cuccurullo V, Gaeta MC. Hybrid SPECT/CT Imaging in Neurology. Curr Radiopharm. 2014; 7(1): 5-11. [CrossRef] [PubMed Abstract]

[53] Krause BJ, Schwarzenböck S, Souvatzoglou M. FDG-PET and PET/CT. Recent Results Cancer Res. 2013; 187: 351-369. [CrossRef] [PubMed Abstract] 
[54] Karantanis D, Kalkanis D, Allen-Auerbach M, et al. Oncologic ${ }^{18}$ F-FDG PET/CT: referring physicians' point of view. J Nucl Med. 2012; 53(10): 1499-1505. [CrossRef] [PubMed Abstract]

[55] Evangelista L, Mezzato C, Felloni G, Saladini G. Current and future perspectives in diagnostic imaging as a guide to targeted/local therapies in breast cancer recurrence. $Q \mathrm{~J} \mathrm{Nucl} \mathrm{Med} \mathrm{Mol}$ Imaging. 2013; 57(4): 367-380. [PubMed Abstract]

[56] Antunovic L, Rodari M, Rossi P, Chiti A. Standardization and quantification in PET/CT imaging: tracers beyond FDG. PET Clin. 2014; 9(3): 259-266. [PubMed Abstract]

[57] Nasrallah I, Dubroff J. An overview of PET neuroimaging. Semin Nucl Med. 2013; 43(6): 449461. [CrossRef] [PubMed Abstract]

[58] McArdle B, Dowsley TF, Cocker MS et al. Cardiac PET: metabolic and functional imaging of the myocardium. Semin Nucl Med. 2013; 43(6): 434-448. [PubMed Abstract]

[59] Holland JP, Cumming P, Vasdev N. PET radiopharmaceuticals for probing enzymes in the brain. Am J Nucl Med Mol Imaging. 2013; 3(3): 194-216. [PubMed Abstract]

[PMC Free Article]

[60] Shetty D, Lee YS, Jeong JM. (68)Ga-labeled radiopharmaceuticals for positron emission tomography. Nucl Med Mol Imaging. 2010; 44(4): 233-240. [PubMed Abstract]

[PMC Free Article]

[61] Prior JO, Allenbach G, Valenta I, et al. Quantification of myocardial blood flow with ${ }^{82} \mathrm{Rb}$ positron emission tomography: clinical validation with ${ }^{15} \mathrm{O}$-water. Eur J Nucl Med Mol Imaging. 2012; 39(6): 1037-1047. [CrossRef] [PubMed Abstract]

[62] Wollenweber T, Bengel FM. Cardiac Molecular Imaging. Semin Nucl Med. 2014; 44(5): 386397. [CrossRef] [PubMed Abstract]

[63] Fowler AM. A molecular approach to breast imaging. J Nucl Med. 2014; 55(2): 177-180. [CrossRef [PubMed Abstract]

[64] Mansi L, Cuccurullo V, Ciarmiello A. From Homo sapiens to Homo in nexu (connected man): could functional imaging redefine the brain of a 'new human species'? Eur J Nucl Med Mol Imaging. 2014; 41(7): 1385-1387. [PubMed Abstract]

[65] Parus JL, Mikolajczak R. Beta-emitting radionuclides for peptide receptor radionuclide therapy. Curr Top Med Chem. 2012; 12(23): 2686-2693. [PubMed Abstract]

[66] Brady D, Parker CC, O'Sullivan JM. Bone-targeting radiopharmaceuticals including radium223. Cancer J. 2013; 19(1): 71-78. [CrossRef] [PubMed Abstract]

[67] Wunderlich G, Schiller E, Bergmann R, Pietzsch HJ. Comparison of the stability of Y-90-, Lu177- and Ga-68- labeled human serum albumin microspheres (DOTA-HSAM). Nucl Med Biol. 2010; 37(8): 861-867. [CrossRef] [PubMed Abstract]

[68] Allen BJ. Clinical trials of targeted alpha therapy for cancer. Rev Recent Clin Trials. 2008; 3(3): 185-191. [CrossRef] [PubMed Abstract]

[69] Kitson SL, Cuccurullo V, Moody TS, Mansi L. Radionuclide antibody-conjugates, a targeted therapy towards cancer. Curr Radiopharm. 2013; 6(2): 57-71. [CrossRef] [PubMed Abstract] 
[70] Coleman R, Aksnes A-K, Naume B, et al. A phase IIa, nonrandomized study of radium-223 dichloride in advanced breast cancer patients with bone-dominant disease. Breast Cancer Research and Treatment. 2014; 145(2): 411-418. [CrossRef] [PubMed Abstract]

[71] Tan Z, Chen P, Schneider N, et al. Significant systemic therapeutic effects of high-LET immunoradiation by ${ }^{212} \mathrm{~Pb}$-trastuzumab against prostatic tumors of androgen-independent human prostate cancer in mice. Int J Oncol. 2012; 40(6): 1881-1888. [PubMed Abstract]

[72] Sadeghi M, Enferadi M, Tenreiro C. Nuclear Model Calculations on the Production of Auger Emitter ${ }^{165}$ Er for Targeted Radionuclide Therapy. J Mod Phys. 2010; 1(4): 217-225.

[Reference Source]

[73] Brechbiel MW. Bifunctional chelates for metal nuclides. Q J Nucl Med Mol Imaging. 2008; 52(2): 166-173. [PubMed Abstract] [PMC Free Article]

[74] Rambaldi PF, Cuccurullo V, Briganti V, Mansi L. The present and future role of (111)In pentetreotide in the PET era. Q J Nucl Med Mol Imaging. 2005; 49(3): 225-235.

[PubMed Abstract]

[75] Giovannini E, Gaeta M, Ciarmiello A. ${ }^{68}$ Ga-Somatostatin analogue PET/CT in neuroendocrine tumors. J Diagn Imaging Ther. 2014; 1(1): 81-102. [CrossRef]

Citation: Mansi L, Kitson SL, Cuccurullo V, Ciarmiello A. Basic premises to molecular imaging and radionuclide therapy. Journal of Diagnostic Imaging in Therapy. 2014; 1(1): 137-156.

http://dx.doi.org/10.17229/jdit.2014-1125-010

Copyright: (C) 2014 Mansi L, et al. This is an open-access article distributed under the terms of the Creative Commons Attribution License, which permits unrestricted use, distribution, and reproduction in any medium, provided the original author and source are cited.

Received: 04 November 2014 | Revised: 20 November 2014 | Accepted: 21 November 2014

Published Online 25 November 2014 (http://www.openmedscience.com) 